\title{
The Case Against Cognitive Phenomenology
}

\author{
Peter Carruthers and Bénédicte Veillet
}

The goal of this chapter is to mount a critique of the claim that cognitive content (that is, the kind of content possessed by our concepts and thoughts) makes a constitutive contribution to the phenomenal properties of our mental lives. We therefore defend the view that phenomenal consciousness is exclusively experiential (or nonconceptual) in character. The main focus of the chapter is on the alleged contribution that concepts make to the phenomenology of visual experience. For we take it that if cognitive phenomenology is to be found anywhere, it should be found here. However, we begin with a discussion of the question of cognitive phenomenology more generally, and we close by sketching how our argument might be extended into the domain of nonperceptual thought.

\section{Introduction}

We take our start from a problem raised by Bayne (forthcoming): how is the debate over the alleged existence of cognitive phenomenology to be adjudicated? On the one hand, there are those who insist that only the nonconceptual contents of experience are ever phenomenally conscious (e.g. Tye 1995, 2000). On the other hand, there are people who declare it to be introspectively obvious that thoughts, too, are like something to undergo, in the relevant sense (e.g. Strawson 1994; Siewert 1998). Bayne reviews these debates, arguing that they resist resolution and that our grasp of what is at stake is much less secure than one might initially have thought. We will suggest a way forward. Similarly, Schwitzgebel (2008) uses the apparent irresolvability of the question of cognitive phenomenology to argue for the unreliability of introspection itself. In this, however, he oversteps the mark. For the main point at issue, we will suggest, is whether cognition is implicated in phenomenal consciousness constitutively or just causally. And this isn't a difference that should always be accessible to introspection, on anyone's view of the latter. 


\section{PETER CARRUTHERS AND BÉNÉDICTE VEILLET}

No one denies that thoughts are (sometimes) ${ }^{1}$ associated with phenomenal qualities, or that it can be like something to entertain a thought. For some thoughts can be expressed in "inner speech" or can be accompanied by visual imagery, where the latter properties are, of course, phenomenally conscious. It is therefore a delicate matter to say precisely how the question of cognitive phenomenology should be formulated. Is it the question whether (some) thoughts possess phenomenal attributes intrinsically? We believe not (at least if "intrinsic" means "non-relational"). For it is very much disputed whether experiences possess their phenomenal character intrinsically (non-relationally), even amongst those who are realists about phenomenal consciousness. Thus, there are those who think that the phenomenal properties of an experience can be reductively explained in terms of the relations that the state in question bears to other things. (This is true of reductive representationalists about phenomenal experience, for example, whether of a first-order type-Dretske 1995; Tye 1995—or of a higher-order sort—Lycan 1996; Carruthers 2000; Rosenthal 2005.) The same range of options should surely be available to those who believe in cognitive phenomenology.

Is the question then whether the phenomenal characters associated with (some) thoughts are constitutive of those thought-types? If someone entertains a thought with a certain phenomenal character, should our question be whether anyone could count as entertaining the very same thought if her thought did not have that phenomenal character? This still isn't right. For one could surely believe that thoughts are to be individuated in terms of their content alone (together with their causal role, perhaps) while nevertheless believing in cognitive phenomenology. In which case someone might count as entertaining the very same thought even if its phenomenal properties were different (in something like the way that the very same thought can be entertained in English or in French, for example), or even if its phenomenal properties were absent altogether.

Is the question then whether a thought is (sometimes) a constitutive part of a given phenomenally conscious mental episode? Is the idea that no one could undergo the very same phenomenally conscious episode who didn't entertain the thought in question? Thus, one might claim that no one could enjoy the exact same phenomenology that one does when one says to oneself in inner speech, "Red is a primary color," who did not at the same time entertain the thought that red is a primary color. (One might claim, for example, that the phenomenology of a monolingual French speaker rehearsing the exact same sounds would be different.) Would this be enough to demonstrate the existence of cognitive phenomenology? Although this gets us closer, it is still not quite right. For as we will see in more detail later, a thought could be a constitutive part of a phenomenally conscious event without making a constitutive

\footnotetext{
${ }^{1}$ The qualification is needed because most of us will allow that thoughts can occur unconsciously, and that as such they don't possess phenomenal qualities (just as most will now allow that there are accessunconscious perceptual states that lack phenomenal attributes).
} 
(as opposed to a causal) contribution to the phenomenal properties of that event. Thus consider the following analogy. When one bakes a cake, one mixes together water, flour, eggs, sugar, and perhaps other ingredients. The result is sweet to the taste. But although the water forms a constitutive part of the cake, it makes no direct contribution to its sweetness. Likewise, it may be that the cognitive content of any given phenomenally conscious state, although a proper part of the latter, makes no direct contribution to its phenomenal qualities.

We suggest that the question before us is this: concerning some phenomenally conscious events, is it true that a thought occurring at the same time (perhaps as a constitutive part of the event) makes a constitutive, as opposed to a causal, contribution to the phenomenal properties of those events? (We intend this formulation to be understood in such a way as to cover any instance where a thought is identical with a given phenomenally conscious event, as a limiting case of the constitution-relation.) Those who believe in cognitive phenomenology will answer this question positively. Those who think that thoughts per se lack phenomenal properties will answer it negatively (while allowing, of course, that thoughts are often associated with phenomenal properties, and that they will often make a causal difference to one's phenomenally conscious mental life).

We should stress that this way of construing the question of cognitive phenomenology is rather different from that commonly found in the literature, and in many of the other chapters in this book. But most writers neglect to draw the causal/constitutive distinction in their arguments. Once that distinction is held clearly in mind, however, it should be plain that what is really at stake in these debates is whether thoughts and concepts make a constitutive contribution to the phenomenal properties of events in which they are embedded. ${ }^{2}$

Our construal of the question of cognitive phenomenology might be challenged. If one is to demonstrate the reality of cognitive phenomenology, why shouldn't it be enough to establish that concepts make a causal contribution to phenomenology? Who gets to say that the question of cognitive phenomenology has to be understood constitutively and not causally? By way of reply, consider first the debate about the cognitive phenomenology of perception. Here the causal question has never been in dispute. Tye $(1995,2000)$, for example - who has been one of the main champions of

\footnotetext{
${ }^{2}$ Some contributors to this volume think that the question of cognitive phenomenology is really the question whether occurrent thought has a proprietary or sui generis phenomenology. Thus, Pitt (this volume) thinks that the question is whether thoughts have a phenomenology that is as unlike auditory or visual phenomenology as the latter are unlike each other. And Kriegel (this volume) thinks that the question is whether thoughts have phenomenal properties that don't reduce to some other, already familiar, forms of perceptual or somatic phenomenology. These characterizations are stronger than ours. For if cognitive phenomenology is sui generis (in either of these senses) then it must follow that the thought-content in question makes a constitutive (and not just a causal) contribution to the phenomenal properties of our mental lives. But the reverse doesn't hold: concepts might make a constitutive contribution to phenomenology even if the resulting phenomenal properties aren't sui generis. Our critique of the idea of cognitive phenomenology, as we characterize it, will thus apply equally to these stronger understandings.
} 
the claim that phenomenal consciousness is exclusively nonconceptual-has always insisted that concept deployment nevertheless has a causal impact upon phenomenology. Indeed, once the causal/constitutive distinction is duly noted, this seems so obvious as to be barely worth asserting. What is true, however, is that discussions of cognitive phenomenology have often failed to draw the distinction in question explicitly. As a result, theorists will frequently move illicitly from causal claims (or claims that are best interpreted causally) to constitutive ones.

Now consider the debate over the phenomenal properties of non-perceptual thoughts and judgments. It would be foolish to try to make a controversy out of claiming that such thoughts, as well as perceptual experiences, have phenomenal properties (as defenders of cognitive phenomenology characteristically wish to do), unless what is meant is that thoughts make a constitutive contribution to our phenomenal lives. For of course everyone allows that what one thinks can make a causal difference to what one experiences. For depending on what one is thinking about one will direct visual attention in one direction or another, engage in inner speech or manipulate visual images, and so forth, all of which will result in changes in one's phenomenal experience. Hence the claim of cognitive phenomenology, if it is to be at all interesting, needs to be construed constitutively and not merely causally.

Although our ultimate target is the question whether thoughts of any kind make a constitutive contribution to phenomenology, we will mainly focus on a narrower issue (discussed in Sections 2 and 3). This is the question whether or not concepts (or perceptual judgments) make a constitutive difference to the phenomenology of our perceptual experience. At the outset of this discussion we will assume that the question should be framed in terms of the vexed conceptual/nonconceptual distinction, before generalizing to approaches that deny any such distinction. The lessons that we learn in addressing this issue will then carry over to the question of the phenomenal contribution of non-perceptual thought, which will be discussed more briefly in Section 4 .

\section{Concepts in experience}

Tye $(1995,2000)$ is adamant that experiences possess nonconceptual content, and that only states with such content (including bodily sensations, visual and auditory images, and emotional feelings) are phenomenally conscious. He claims, furthermore, that phenomenal consciousness is exhausted by such content. If he is correct, then there is no cognitive phenomenology in the sense that concerns us. Carruthers (2000) agrees with the first two of Tye's claims, pointing to the richness and fineness of grain of our perceptual and imagistic states, and arguing that these are the properties that give rise to the phenomenality of experience. Carruthers also argues, however, that our experiences are often imbued with concepts, and that these make an important contribution to the phenomenal content of those experiences. We will briefly review and critique his arguments, together with a more recent argument by Bayne (2009). The result will be a stand-off, which we will attempt to resolve in Section 3. 


\subsection{Arguments from phenomenal change}

One of the arguments in Carruthers (2000) is that concept acquisition can transform the phenomenology of one's experience. This is familiar to common sense, and is also confirmed experimentally. When one first takes up birdwatching, for example, one's experience of the birds that one observes will be comparatively impoverished. One might only see collections of little grey birds on a beach, for instance. But having learned to distinguish knots from plovers from redshanks, one sees them as such. And it doesn't seem correct to gloss what takes place in such learning by saying that one's experiences stay the same but are now accompanied by differences in belief. On the contrary, having acquired the relevant concepts, the differences between the birds jump out at one phenomenologically.

In a related set of experiments, Livingston et al. (1998) trained subjects to categorize shapes into Zofs and Gexs. The differences between the two shape-types were fairly minor, and subjects rarely became explicitly aware of their distinguishing features. Nevertheless, with time, all subjects became quite reliable at recognizing instances of the two concepts. The experimenters collected similarity-ratings at both the start and the end of the experiment. At the start, subjects rated Zofs and Gexs as very similar to one another, but by the end their similarity ratings had been pushed quite far apart. Subjects now saw shapes of the two types as dissimilar to one another, even though they couldn't (for the most part) articulate the difference.

Carruthers (2000) also draws attention to the familiar fact that deployment of one or another concept in one's experience can transform the phenomenology of the latter. This is especially clear in the case of ambiguous figures like the famous duck-rabbit. Although the figure itself remains unchanged (and likewise with it, one might be tempted to think, the nonconceptual content of one's experience, representing a particular arrangement of lines on a plane surface) one can dramatically shift the phenomenology of the experience at will. By deploying the concept duck one sees the figure as a duck, and by deploying the concept rabbit one sees it as a rabbit. ${ }^{3}$

These arguments aren't successful as they stand, however. They fail to establish that the phenomenal qualities of a state aren't exhausted by its nonconceptual content. For they don't distinguish between the causal and constitutive contributions that concepts might make to the phenomenology of experience. When one acquires a new concept one learns to attend preferentially to those features of its instances that are distinctive of them. To recognize a plover, for example, one needs to look for the dark ring around its neck. And to distinguish knots from redshanks one needs to pay attention, inter alia, to the length and coloring of the legs. These forms of attention can either be overt, in the form of increased numbers of saccades to the relevant features, or covert, devoting extra processing to information deriving from the relevant portions of the visual field.

\footnotetext{
3 Throughout we will understand concepts to be individuated by their contents (whether wide or narrow; on this we remain neutral, see section 3.2.), rather than by their vehicles. We refer to them using italics.
} 
And indeed, subjects who wear eye-trackers while viewing ambiguous figures show different patterns of overt attention under the two viewing conditions (Pylyshyn 2003). It is hardly surprising, then, that the phenomenology of one's experience should differ in the two cases. This is because the concepts that one deploys have a causal impact, via patterns of attention, on the nonconceptual contents that result from the normal operations of the visual system.

Opponents of nonconceptualism might attempt to reply to this critique, relying on the assumption that causes cannot be simultaneous with their effects. For the contribution that concepts make to the phenomenology of experience can seemingly be simultaneous with the experience itself. One does not (normally) first see a little grey bird on a beach and then (having categorized it as a plover) see it as a plover. Rather, one can see the bird as a plover at first glance. It seems to follow that the contribution that concepts make to the phenomenology of experience cannot be causal and must therefore be constitutive. This reply is ineffective, however, because there is every reason to think that concepts do their work in perception unconsciously, in interactions with the incoming nonconceptual representations within the visual system before any representations become conscious (Kosslyn 1994). So the contribution made by concepts to one's perceptual phenomenology can be merely causal even if there isn't any time differential discernable within phenomenal experience itself.

Although an appeal to the non-simultaneity of causation doesn't help, the argument from concept acquisition can seemingly be bolstered from another direction. For similar data exist for the acquisition of color concepts, where it might appear that patterns of attention are unlikely to have any impact (Burns and Shepp 1988). Consider people who view two red cards, one of which is painted a uniform shade of scarlet and the other of which is painted a uniform shade of vermillion. And suppose that at this point subjects only possess the generic concept red. Asked to rate the similarity of the two cards, subjects are inclined to place them pretty close to one another on a color similarity-scale. But now the subjects undergo training, and become proficient with the concepts scarlet and vermillion. Asked to rate the similarity of the same two cards once again, subjects now mark them as less similar to one another than they had done before. This effect can't be explained by changes in patterns of overt attention. For since each of the cards is uniformly colored, the very same data will result for the visual system to process no matter how one saccades over them. Yet what the two cards are like for subjects has changed. This might be taken to suggest that concept acquisition can make a constitutive difference to the phenomenology of one's experience.

Unfortunately, these data can't rule out the possibility that changes in patterns of covert attention are responsible for the changes in phenomenology. For as is well known, colors can be analysed along three different dimensions-hue, saturation, and intensity. While we have no positive evidence that this is the case, it may be that training in color discrimination, of the sort reported by Burns and Shepp (1988), has the effect of enabling subjects to pay differential attention to (and hence to devote 
increased cognitive resources to processing) the different dimensions. This would have an effect on the nonconceptual contents that result.

In any case, however, the color data also admit of an alternative explanation. This is that subjects, post-training, judge the two shades to be unlike one another simply because they are thought to belong to two different categories. The phenomenology of their experience of the two colors can be unchanged. Here is how the story would go. If one is asked how similar two shades of color are, where both fall under the only relevant concept that one has (red, say), then one might expect the answer to be a confluence of two factors: (1) both are the same insofar as both are red; (2) they are different depending on how far apart they are along the color spectrum. But now if (post-training) one looks at those same two shades, one of which is scarlet and the other of which is vermillion, one will judge them to be categorically distinct, because each falls under a distinct concept. When asked how similar the colors are, therefore, one might express greater dissimilarity than one did previously. But what one is really expressing is one's belief that the shades are different in type (because they belong to different categories). Consistent with that, the phenomenology of one's experience of the shades might be unchanged. And even if subjects were asked to comment explicitly on their phenomenology (rather than on the colors themselves, as was actually the case in these experiments), and were to express greater dissimilarity following conceptacquisition, this could be dismissed as a case of "cross-contamination" from first-order judgments of difference to higher-order ones.

The arguments from phenomenal change turn out to be inconclusive, then. They don't allow us to determine whether concepts make a contribution to the phenomenology of experience that is constitutive rather than merely causal.

\subsection{An argument from vision science}

Carruthers (2000) offers a further argument for the thesis that concepts can make a constitutive contribution to phenomenally conscious experience. This depends upon two premises. The first is that phenomenally conscious experience is co-extensive, at least, with the global broadcast of perceptual and imagistic information in the brain. There is widespread evidence that this is so (Baars, 2002; Dehaene and Naccache, 2001; Dehaene et al., 2003). Not everyone agrees, of course, that global broadcast per se is sufficient for phenomenal consciousness. Indeed, Carruthers himself will claim that it is only sufficient given the presence of a properly functioning higher-order thought faculty which serves as one of the consumers for the global broadcasts. And many more will deny that it provides a successful reductive explanation of phenomenal consciousness. But neither of these sources of disagreement matter for present purposes. Even property-dualists about phenomenal consciousness can accept the co-extensiveness claim (as does Chalmers 1997, for example). ${ }^{4}$

\footnotetext{
4 That claim will nevertheless be denied by those who, like Block $(1995,2002)$, think that there are access-unconscious states that possess phenomenal properties. But even Block will accept that globally
} 
The second premise of the argument is that conceptual representations are globally broadcast alongside (or rather, bound into) the nonconceptual representations that trigger their activity. This is supported by the work of Kosslyn (1994) and others, which suggests the following model of the operations of the visual system. The initial nonconceptual outputs of early vision are monitored by a whole host of conceptual systems, each of which uses a battery of conceptual "templates," attempting to achieve a best match with the nonconceptual data. When one is found, the relevant concept is attached to the nonconceptual representation in question and globally broadcast along with it, for other concept-wielding consumer systems to take note of and draw inferences from.

Now, if globally broadcast percepts and phenomenal consciousness coincide with one another, and if concepts often form a constitutive part of the global broadcast, then that might be taken to imply that phenomenal consciousness, too, is partially constituted by concepts. And so it will turn out that elements of cognition-specifically, concepts-make a constitutive, and not just a causal, contribution to the phenomenology of experience. But this argument, like the argument from concept acquisition, misses its mark. From the fact that a given concept is a constitutive component of a phenomenally conscious perceptual state it doesn't follow that the concept makes a constitutive contribution to the phenomenal qualities of that state. So far as the phenomenology goes, it might be that perceptual states carve cleanly into two types of component: their nonconceptual content, which is wholly responsible for their phenomenal properties, and their conceptual content, which makes no constitutive contribution to that phenomenology.

\subsection{An argument from visual agnosia}

Bayne (2009) suggests that pure cases of visual agnosia can be used to support the existence of cognitive phenomenology. Such patients perceive colors and shapes normally. For example, a patient might be capable of accurately copying a drawing of a pipe or a toothbrush. But he will be incapable of recognizing the object as such. The condition is characterized by an inability to apply concepts in one's visual experience of the world (although the concepts themselves, and the semantic knowledge that goes with them, remain undamaged). This appears to have a significant impact on visual phenomenology. For the descriptions that agnosic patients provide of their experience, while they struggle to make sense of the world around them, suggest that their experience is very different from normal (Rubens and Benson 1971; Farah 2004). But there is nothing here, as yet, to demonstrate that the contribution that concepts would normally make to the phenomenology of experience is constitutive rather than merely causal. For it may be that the causal connections between the 
agnosic patient's concepts and the visual system, which would normally be used to direct visual search and visual processing, have been broken.

It might be questioned whether different patterns of attention alone can be responsible for all of the phenomenal differences between associative agnosia and normal forms of visual perception, however. Granted, when an agnosic person looks at an object the nonconceptual content of the resulting experience will differ from that of a normal person, caused by differences in attention and visual search. But there will surely be many more phenomenal disparities here than would occur within the experience of a normal person who first sees an ambiguous figure as a duck and then sees it as a rabbit. Indeed, this is so. But it is far from clear that differences lend any real support for cognitive phenomenology. For the visual world makes little sense to an agnosic patient. He sees colors and shapes, but not tables, chairs, or people. Hence the world of an agnosic patient will be very different from normal. But while this difference might cause differences in perceptual phenomenology, it is unclear that it itself constitutes a phenomenal difference. Moreover, the patient's visual experience will be accompanied by feelings of anxiety and puzzlement, and object-identification, when it occurs, will be slow and effortful. Since these states are phenomenal ones, what it is like to be an agnosic person will be markedly different from what it is like to be a normal visual perceiver. But the differences are ones that appear to be caused by the absence of visual identification from visual experience (and hence by the absence of concepts from visual contents), rather than being constituted by the latter.

\subsection{A generalized stand-off}

Up to this point we have assumed the existence of a real distinction between conceptual and nonconceptual content. Does the question of the contribution that concepts make to the phenomenology of experience look any different if one denies this distinction? We believe not. Consider McDowell (1994), for example. He thinks that the difference between thought and experience lies not in the presence and absence of concepts (both are equally conceptual), but rather in the comparative fineness of grain and large numbers of indexical concepts that go to make up experience. The concepts that figure in our thoughts, in contrast, are comparatively coarse-grained, and only a handful can be entertained at any one time. Suppose that some version of the global broadcast story about conscious experience is also endorsed. So suppose that a given phenomenally conscious experience will normally be composed of both a large number of fine-grained indexical concepts and a few coarse-grained concepts (such as the concept red). Does it follow that the latter will make a constitutive contribution to the phenomenology of the experience? It does not. It might be that phenomenal properties are determined entirely by the fine-grained and rich character of the experience, and that any contributions made by the sorts of coarse-grained concepts that can also figure in our non-perceptual thoughts are purely causal.

What we have so far, then, is a stand-off. This closely parallels the stand-off that Bayne (forthcoming) describes between opponents and defenders of the view 
that thoughts, per se, are ever phenomenally conscious (although we have offered different arguments). It seems that neither side has a decisive case against the other, and it is hard to see how to make progress in resolving the dispute. What we will now argue, however, is that we can, indeed, make progress if we assume that phenomenally conscious features are those that give rise to the so-called "hard problem" of consciousness.

\section{Do concepts contribute to the hard problem?}

Here is the proposal: concepts should only count as making a constitutive contribution to the phenomenally conscious aspects of experience if they also make such a contribution to the main respects in which phenomenal consciousness is thought to be problematic or puzzling. To get the flavor of how this might go, consider ineffability, which has often been thought to be a property of conscious experience. We have difficulty articulating or describing the properties of our phenomenally conscious experience. When we try to say what it is like to see red, or smell a rose, or taste coffee, we are reduced to gesturing toward the properties that our experiences are of. We say, for example, "It is the experience that I undergo when I see/smell/taste that." It is plain, however, that ineffability (insofar as it exists) is a property of the nonconceptual content of our experience only (specifically its fineness of grain). For there is no problem whatever in expressing the conceptual content of our experience. We can say that it is of red, or of a rose, or of coffee, thereby deploying the very concept that is globally broadcast as part of the experience itself. ${ }^{5}$

The main puzzle about phenomenal consciousness, however, concerns how it can exist in a physical world. This is the so-called "explanatory gap." People find it hard to see how any physical story could fully explain the qualities that we are aware of in our experience. For in respect of any such story that we are offered, we can see in advance that we shall be capable of thinking, "But all of that might be true while these qualities of this experience were different or absent." So we need to ask whether any such gap exists with respect to the concepts that figure in our experience. ${ }^{6}$

\footnotetext{
${ }^{5}$ Of course a similar point can be made (with just a few adjustments) from the perspective of those who deny the existence of nonconceptual content. Such people can say that the ineffability of experience is due entirely to the fine-grained indexical concepts that compose it, and owes nothing to the presence within the experience of coarse-grained thought-concepts such as red.

${ }^{6}$ We will develop our argument throughout on the assumption that the explanatory gap is real. This is because we believe in conceptually isolated phenomenal concepts (see Section 3.1), and because, given the existence of such concepts, it is plain that the gap-inducing thought experiments really are coherent. We actually believe, however, that a version of our argument could be acceptable to so-called "Type A" materialists who deny the conceivability of the gap. For even Type A materialists allow that there is at least the illusion, or appearance, of an explanatory gap. As we will see in Section 3.2, however, once the question of cognitive phenomenology is correctly framed, then it is obvious that there is no explanatory gap with respect to the conceptual components of experience.
} 
Here, in summary form, is the argument that we will develop:

(1) A property is phenomenal only if it contributes to the hard problem of consciousness, and in particular, only if it gives rise to an explanatory gap.

(2) A property gives rise to an explanatory gap only if we have a conceptually isolated phenomenal concept for it (such as the concept these qualities deployed in the thought just quoted in the paragraph above).

(3) So a property is phenomenal only if we have a conceptually isolated concept for it.

(4) We lack conceptually isolated concepts for any cognitive/conceptual properties of experience (that is to say, for experiences individuated in such a way as to include their cognitive/conceptual components).

(5) So cognitive/conceptual properties don't give rise to an explanatory gap.

(6) Hence cognitive/conceptual properties aren't themselves phenomenal ones.

If the conclusion in (6) can be established, then it will follow that concepts make, at best, a causal contribution to the phenomenal properties of experience. We take it that premise (1) would be widely agreed upon (although we will return to consider a challenge to it in Section 3.4). We begin (in Section 3.1) with a brief defense of premise (2) before making the case for premises (4) and (5) in Section 3.2. In examining whether cognitive properties give rise to an explanatory gap, we propose to focus on the conceivability of inverted experience. While a number of different thought-experiments have been deployed in defense of the explanatory gap (including black-and-white Mary and zombies, in addition to cases of inverted experience), not all of these are appropriate in the present context, for reasons that will emerge in Section 3.3.

\subsection{The role of conceptually isolated phenomenal concepts}

It is widely agreed that the explanatory gap depends upon a set of conceptually isolated phenomenal concepts. Indeed, just about everybody in recent debates (both propertydualists and physicalists alike) acknowledges the crucial role that these concepts play in the explanation of explanatory gaps, inverted-experience thought-experiments, and so forth (Loar 1990; Chalmers 1996, 2007; Balog 1999; Carruthers 2000; Tye 2000; Papineau 2002; Stoljar 2005; Carruthers and Veillet 2007; Levine 2007). The dispute between dualists and physicalists is (for the most part) about whether phenomenal concepts can be used to provide an adequate explanation of the gap without appealing to any non-physical properties, not about whether phenomenal concepts are necessary for a gap. And the crucial thing about phenomenal concepts is that they should have the right sorts of conceptual isolation from physical and functional concepts, together with bearing the right sorts of immediate relations to their referents. (Perhaps they are indexical and/or recognitional concepts of a certain sort; see Loar 1990; Carruthers 2000; Perry 2001; or perhaps they actually contain, by quoting, the experiences that they are about; see Balog 1999; Papineau 2002. We will explore these possibilities in Section 3.2.) It is this isolation from other sorts of concepts that underpins the 
conceivability of zombies and inverted experiences, and which means that no amount of physical information can entail a priori that any given phenomenal concept should be applied.

We should stress that we are not here meaning to endorse the so-called "phenomenal concept strategy" for reconciling physicalism with the explanatory gap (Carruthers and Veillet 2007; Chalmers 2007). We are only claiming that conceptually isolated phenomenal concepts are a necessary condition for a gap to obtain, not that they are sufficient for explaining it. The phenomenal concept strategy aims to defend the latter thesis (that an appeal to phenomenal concepts is all that is needed to explain the explanatory gap). But all we assume here is the former-rather uncontroversialclaim that we need to possess conceptually isolated concepts for thinking about our experiences in order for the explanatory gap to arise. This might be rejected by socalled "Type A" physicalists like Dennett (1991), who think that zombies and the rest are strictly inconceivable. But it is accepted by almost everyone else. Chalmers (2003), for example, allows the existence of phenomenal concepts, and thinks that he must do so. For if our concepts for our experiences weren't conceptually isolated, then it should be possible for us to discern entailment relations from physical and functional descriptions to phenomenal ones, and there would be no gap.

Here is another way to make the point: assume that the dualist is right and there are non-physical properties after all. This ontological fact could give rise to the conceivability of inverted experiences or of zombies only if the concepts that we use for thinking about the non-physical properties are conceptually isolated from our physical and functional concepts. The explanatory gap is, of course, an epistemic one, and depends upon the conceptual isolation of our concepts, even if the dualist is correct that underlying it is an ontological divide. This, we think, establishes the truth of our second premise: that a property will give rise to an explanatory gap only if we have a conceptually isolated phenomenal concept for it. Once again, this isn't to endorse the idea that phenomenal concepts can be used to defend physicalism. Anti-physicalists like Chalmers (2003) and physicalists like Stoljar (2005) and Tye (2009) can reject the phenomenal concept strategy, while acknowledging that we possess phenomenal concepts of the sort envisaged.

\subsection{No cognitive gap}

We now argue that we do not possess conceptually isolated phenomenal concepts for the conceptual components of experience, and hence that cognitive properties do not give rise to an explanatory gap. Central among the well-known gap-inducing thought-experiments that phenomenal concepts make possible are those that dissociate the phenomenally conscious state in question from its intentional content (either wide, embracing the worldly properties that it is about, or narrow, perhaps characterized in terms of internal cognitive role). This is what happens in an inverted-experience thought-experiment. For example, faced with a particular shade of red, one can think the thought, "This experience might not have been about red, or might not 
have had the content red - it might not have been a seeming of red." Of course this isn't the only variety of inversion thought-experiment. One can also imagine one's experiences having inverted causal roles, say. But inversion of content is surely the central case. (It is this, for example, that underlies the familiar skeptical question about other minds: "How do I know that what I experience when I see red isn't what you experience when you see green?") It should also be emphasized that what is required for an explanatory gap isn't that experience inversion should be genuinely possible (most representational theorists about phenomenal consciousness will deny this), but rather that it is thinkable. Again, the gap that almost everyone agrees upon is an epistemic one.

Consider, then, the thought, "This experience might not have been an experience of red, or might not have had the content red." In order for this thought to be thinkable, it appears that the phenomenal concept that one deploys must be picking out only the nonconceptual content of the experience. For if that concept picked out an experience that contained the concept red as a constituent, ${ }^{7}$ in such a way as to include immediate reference to the latter, then how could the experience not be about red, and how could it not be a seeming of red? Let us grant that the experience has both a nonconceptual and a conceptual content. In which case, if both make a constitutive contribution to the phenomenal qualities of the experience, then the phenomenal concept that one deploys must engage with both aspects. Yet if the experience that one refers to with one's phenomenal concept has the content $\left[\operatorname{red}_{17}, r e d\right]$, then how could one coherently think, of a state with that content, "This might not have been about red"? For the concept red will be right there in the content of the state that one's phenomenal concept picks out, and it is of the essence of that concept that it should be about red. ${ }^{8}$

Does this argument presuppose externalism about conceptual content? We believe not. The thought-experiments that give rise to an explanatory gap are generally believed to be independent of any particular theory of content. It is supposed to be content (however characterized) that can be pulled apart in thought from feel. And the same is surely true here. Instead of the thought, "This experience might not have been about red" one can entertain, "This experience might not have had the content red", where content can be characterized internally rather than externally. But if the phenomenal concept this experience in such a thought were to pick out both the (narrow) conceptual and the nonconceptual content of the relevant experience, then it will entail, "The concept with the content red might not have had the content red." This is surely incoherent, on anyone's view, for concepts are individuated in terms of their content.

\footnotetext{
${ }^{7}$ Recall from Section 2.2 that there is evidence that concepts like red are globally broadcast in conscious experience along with the nonconceptual contents that give rise to them.

8 As previously, the same argument will apply mutatis mutandis from the perspective of those who deny the reality of the conceptual/nonconceptual distinction.
} 
By way of bolstering this argument, consider an example where the implied contrast will make it clear that one is referring to both the nonconceptual and the conceptual content of an experience. Suppose that one has been playing with one's perception of a duck-rabbit figure by making it flip back and forth between the two aspects. While one is seeing the figure as a duck, we have every reason to think that the concept duck is deployed as a constitutive part of one's experience. But one cannot coherently think, "This experience (as opposed to that other one, the rabbit-like one) might not have had the content $d u c k$, or might not have involved a seeming of duckishness." Nor does it make any sense to ask, "Why does this experience (the duck-like one) represent a duck as opposed to a rabbit?" When one refers to an experience in such a way that one's thought designates both its conceptual and its nonconceptual content, one can't entertain the sorts of thought-experiments that figure in the hard problem of consciousness. In which case the right conclusion to draw is that the conceptual content of experience doesn't make a constitutive contribution to the phenomenal properties that give rise to that problem.

Let us work through this argument in a bit more detail, once for each of the candidate accounts of phenomenal concepts. Consider the quotational account first (Balog 1999; Papineau 2002). On this view, any thought about a phenomenally conscious experience literally contains that very experience, by quoting it. On such an account the thought, "This experience might not have been about red/might not have had the content red" really has the form, "The experience might not have been about $\mathrm{red} /$ might not have had the content red", where what fills the blank is the very experience in question. But if both the nonconceptual and the conceptual content of the experience figure within this thought, then it will entail the judgment, "The concept red might not have been about red" (if concepts are widely individuated), or it will entail the judgment, "The concept red might not have had the content red" (if concepts are narrow). Either way, the upshot will be incoherent. Since it denies that the quoted item has a property that is in fact essential to it (being about red, or having the content red), it would have the same incoherent status as, "The word 'red' might not have contained three letters."

Now consider an indexical/recognitional theory of phenomenal concepts (Loar 1990; Carruthers 2000; Perry 2001). On such an account it might seem that we can explain the conceivability of inverted experience, even if concepts make a constitutive contribution to phenomenal consciousness. For compare: even if it is conceptually necessary that cats are living beings, one can coherently think, "This might not be/might not have been a living thing," provided that one is unaware that what one's indexical thought picks out is actually a cat. (One might only be aware of a dark shape in the bushes.) Likewise, then, one might be able to think, of an experience of red, "This might not have been about red," provided that one is unaware of the conceptual component of the experience in question.

It is plain that no account of phenomenal concepts that construes them as pure indexicals can be adequate, however. (By a "pure" indexical we mean something 
similar to the indexical "here" in the thought, "I wonder where here is," entertained by someone who has been taken blindfolded to an unknown location. These are indexicals that aren't grounded in an awareness of their referents.) For when we think about our own experiences, or entertain the possibility of zombies or inverted experiences and so forth, we surely take ourselves to be aware of the experiential state in question, in a way that is both more primitive than, and which serves to ground, the application of our phenomenal concept. Yet if the concept red makes a constitutive contribution to the phenomenal properties of the experience and the latter properties serve to ground the application of the recognitional/indexical concept this experience, then the content of the former concept would surely figure in our awareness. But in that case the thought, "This experience might not have had the content red" will be incoherent (however conceptual content is individuated).

It might be replied that one can be aware of an experience in a way that can serve to ground the application of a phenomenal concept without being aware of any of the concepts that are components of that experience. But this doesn't seem right, either. Consider, again, the phenomenon of seeing as. What is one aware of when one is aware of seeing a figure as a duck? Surely the duckishness of the experience figures in the content of one's awareness just as much as does the nonconceptual experience of a certain pattern of lines and shapes. And then if one's phenomenal concept picks out the entire experience (including its conceptual components), one should be incapable of thinking, "This experience might not have been about duckhood," or, "This experience might not have had the content duck."

The same point would surely hold if it were true that concepts ever made a constitutive contribution to the phenomenology of experience. In using a phenomenal concept to pick out those phenomenal properties via awareness of them, one would surely have to be aware of the constituent concepts. For example, if the concept red made a constitutive contribution to the phenomenology of one's experience while one looks at a red tomato, then surely the reddishness of the experience would figure in one's awareness just as much as the fine-grained representation of hue, saturation, and intensity. And then (contrary to fact) one should be incapable of thinking, "This experience might not have been about red, or might not have had the content red."

Suppose one says, then, that phenomenal consciousness is whatever gives rise to the distinctively hard puzzles about consciousness, and one thinks that thoughtexperiments involving inverted experience and explanatory gaps have a central place amongst those puzzles. And suppose one also accepts that conceptually isolated phenomenal concepts are necessary for the puzzles to arise. Then one has reason to say that concepts don't make a constitutive contribution to phenomenal consciousness. Although concepts are constitutive of the globally broadcast outputs of our perceptual faculties, and are hence constitutive of our phenomenally conscious experiences, they make no constitutive contribution to the phenomenal properties of those experiences. 
The phenomenal properties - the properties picked out by our phenomenal concepts-are constituted by the nonconceptual content of our experiences alone. ${ }^{9}$

\subsection{Why inverted experiences?}

We have argued that cognitive properties do not give rise to inverted experience thought-experiments, and hence don't contribute to the hard problem of consciousness. But someone might object that the inference simply isn't warranted. We have focused exclusively on inverted experiences, despite the fact that there are other prominent thought-experiments (zombies, black-and-white Mary) that indicate the existence of the hard problem. Our critic might think that cognitive properties will give rise to Mary-like scenarios or to the conceivability of cognitive zombies and will, as a result, contribute to the hard problem after all. We argue here that the critic is wrong.

Jackson $(1982,1986)$ imagines the case of Mary, who is a famous vision scientist brought up in an entirely black-and-white room, with no experience of color. Many share the intuition that she will learn something new when she leaves the room and experiences red for the first time, suggesting that phenomenal knowledge is something over and above the physical knowledge that she already possesses (which is stipulated to be complete). Can a similar thought-experiment be used to demonstrate that the concepts deployed in our experience likewise make a contribution that seems to defy physical description? Arguably not. (But not, as it turns out, for any reason that counts against the existence of cognitive phenomenology.)

Suppose that Mary is kept in a tomatoless room instead of a colorless one, where she is prevented from ever seeing a tomato (not even a picture of one). Nevertheless, she is given all theoretical knowledge about tomatoes (and about the effects that perceptions of them have on the brain). Will she learn anything new when she is shown a tomato for the first time? Arguably not, but this is because her theoretical knowledge of tomatoes (along with perceptual contact with red things and with roughly round objects) would surely have enabled her to imagine what a tomato looks like. So a defender of cognitive phenomenology can continue to insist that the concept tomato makes a constitutive contribution to the phenomenal experience of seeing a tomato, despite the fact that Mary learns nothing new when seeing a tomato for the first time. For that contribution will already have been made in the tomatoless room, when Mary first imagines a tomato. But equally, the thought-experiment provides no support for such a view.

For rather different reasons the zombie thought-experiment can't be used in support of cognitive phenomenology, either. There are two ways in which such a scenario might be developed: either we imagine a regular zombie who lacks any conscious

\footnotetext{
9 As previously, the same conclusion can be expressed without commitment to the conceptual/nonconceptual distinction. One could say that only the numerous fine-grained indexical concepts that figure in our experiences but not in our thoughts and beliefs ever make a constitutive contribution to phenomenology.
} 
experience whatever; or we try to imagine one who is zombie-like only in respect of the contribution made by concepts to his conscious experience. In the former case, since the zombie fails to have conscious experience at all, it is obvious that we have no way of telling whether the absence of any cognitive contribution to phenomenology is constitutive or merely causal. ${ }^{10}$ The second case appears initially more promising. We might imagine a creature physically and functionally just like us, who does have phenomenally conscious nonconceptual experience, but for whom there is no phenomenal difference between seeing the duck-rabbit as a duck and seeing it as a rabbit. $\mathrm{He}$ experiences just the same pattern of lines on a plane surface in either case, while at the same time being disposed to judge, "It is a duck," on some occasions and, "It is a rabbit," on others. While such a zombie does seem conceivable, it can't help discriminate between the constitutive and causal hypotheses. For we have no way of telling whether the concept-zombie's deficit is that his concepts are incapable of making a constitutive contribution to his phenomenal life, or whether they merely fail to have any causal impact upon the latter. This leaves us with the explanatory gap itself, together with the associated experience-inversion thought-experiments that were the focus of our argument.

\subsection{An attack on the method}

Before concluding this section we need to consider an objection raised by Bayne (forthcoming) against the entire strategy of linking phenomenal consciousness to the various problematic thought-experiments. (This is a challenge to the first premise of the argument summarized at the outset of this section.) The objection is that all of these thought-experiments seem to involve secondary qualities like color. But experiences of primary qualities such as shape and movement can surely be phenomenally conscious also. In which case phenomenal properties aren't exhausted by those that give rise to the hard puzzles.

We agree that in connection with primary qualities it can be harder to construct intuitively convincing examples that parallel the thought-experiments involving inverted color-experiences and so forth. (However, see Thompson 2010, for examples.) In order to provide an example where cube-experiences and sphere-experiences would be inverted with one another, for instance, we would need to construct a highly complex scenario involving worlds where the physical properties of light and reflectance of light are very different, and so on. But this isn't true of all primary qualities. In particular, it isn't true of motion. The existence and effects of spatially

\footnotetext{
${ }^{10}$ Of course one can stipulate that part of what is missing in the case of a complete zombie is the constitutive contribution that concepts make to phenomenology. And if concepts do make such a contribution then they will belong among the elements of mind that give rise to an explanatory gap. But since the zombie thought-experiment is supposed to be pre-theoretically accessible, it is plain that it can't provide any independent support for cognitive phenomenology.
} 
inverting lenses makes it quite intuitive to entertain thoughts like, "This experience [as of movement from left to right] might have represented movement from right to left."

In any case, however, even if it is hard to spell out a detailed description of a world that would render the relevant counterfactual true, one can nevertheless think, "This very [cube-like] experience might not have represented cube-hood." We can coherently entertain the thought that the experience we are undergoing now (a cube-like one) could have had a different functional role and/or a different representational content. No matter how one spells out the different accounts of intentional content (informational, teleosemantic, conceptual role, wide or narrow, and so on) we can see in advance that we will be capable of thinking, in respect of any such account, "I could have had this very experience [a cube-like one] in the absence of the relevant representational state, and vice versa." No matter what functional and/or representational account is provided, one can still think that one could have had the same experiences without the functional and/or representational basis, or could have had the same basis without the experience. And that is the explanatory gap.

We conclude, therefore, that our methodology is sound: phenomenal consciousness can be equated with whatever gives rise to the various "hard problem" thoughtexperiments. And given the soundness of that methodology, it turns out that concepts do not make a constitutive contribution to the phenomenal qualities of our experience.

\section{Against a phenomenology for thought}

We take ourselves to have shown that there is no such thing as cognitive phenomenology in the case of perception. The arguments that have been offered in support of the idea are inconclusive (Section 2), and we have offered what we take to be a powerful argument against it (Section 3). In the present section we propose to sketch how our arguments might be extended into the domain of non-perceptual thought.

\subsection{Inconclusive arguments}

As we have already noted, everyone allows that there are phenomenal properties associated with and/or caused by our thoughts. The real question is whether cognitive content ever makes a constitutive contribution to phenomenology. We think that some combination of the points already made in our discussion of perceptual phenomenology can be deployed to undermine the various arguments that have been offered. For example, the fact that there is a phenomenological difference between hearing one and the same utterance with and without understanding (Strawson 1994; Siewert 1998; Pitt 2004) can be explained in terms of the different patterns of attention to the sound stream that will occur in the two cases (c.f. the duck-rabbit), together with the presence of feelings distinctive of what psychologists call "fluency" in the one case and puzzlement in the other (c.f. visual agnosia).

These factors seem unlikely to play a role in the phenomenal differences that can occur when one adopts one or another interpretation of a single token utterance, 
however, such as, "He has gone to the bank" (Pitt 2004). But of course there will be differences within what might be called the subject's "total phenomenal field" that either cause or are caused by one or another interpretation. (These might include images of dollar bills or perceptions of a nearby river.) Moreover, there is a danger of "cross-contamination" here, similar to the one we noted when discussing the difference that color-concepts might make to the phenomenology of color experience. If one is asked to report on what it is like to be thinking about a financial institution versus what it is like to be thinking about a riverbank, one's answer may be contaminated by the fact that banks themselves (the financial institutions) are very different from river banks. These are two very different kinds of thing, falling under distinct categories. Since money-banks are quite unlike riverbanks, one might naturally say that thinking about the former is very different from thinking about the latter, even if the two events are phenomenologically indistinguishable.

Some people have claimed that it is possible to entertain purely propositionalunsymbolized, imageless - thoughts, and that it is nevertheless like something to think such a thought. For example, Siewert (1998) describes how he was once standing in front of his apartment door, with his hand fumbling in an empty pocket where he would normally keep his keys. He says that at that moment he was wondering where he had left his keys, but without any imagery relevant to such a thought passing through his mind. However, the possibility of cross-contamination in judgments of "what is it like" returns in spades with this sort of example. For of course the location of one's keys is a very different thing from any other object or state of affairs that one might be thinking about, such as the likelihood of a pizza dinner. Because the location of one's keys is very different from the likelihood of a pizza dinner, one will naturallyand correctly-report that thinking about the former is very different from thinking about the latter. But for all that, unsymbolized thinking might be wholly lacking in phenomenology.

It is hard to establish whether episodes of propositional thinking in the absence of imagery are genuinely phenomenally conscious. In which case we have another stand-off. Subjects may report their occurrence, of course. That is enough to make them access conscious (Block 1995). But it isn't sufficient for phenomenal consciousness. ${ }^{11}$ Moreover, it is true that subjects will be dumbfounded if asked to say what it is like to be wondering where one's keys are in the absence of any imagery. Very likely, all that they will be able to say in reply is: it is like wondering where one's keys are. And it might be said that this is not unlike the dumbfounding that occurs when people are asked to say what the smell of a rose is like, or the taste of coffee. But this

\footnotetext{
11 Someone might object that access consciousness is widely believed to be nomologically sufficient for phenomenal consciousness. But this argument begs the question at issue. Granted, we have reason to think that the access consciousness of perceptual states is (via global broadcast) nomologically sufficient for their phenomenally conscious status. But we only have reason to think that this law extends to access-conscious cognitive states if such states are likewise phenomenally conscious. And that is just what is at stake in our current discussion.
} 
doesn't amount to evidence in favor of the phenomenal consciousness of the thought, because an equally possible explanation for the dumbfounding is that there is nothing that it is like to entertain the thought, except that one knows that one is thinking it.

\subsection{Conceptually isolated concepts of thought?}

If thought-contents are to be phenomenally conscious, then they should give rise to an explanatory gap. And if they give rise to an explanatory gap, then we should possess some conceptually isolated concepts for them. Could there be recognitional concepts for our thought-contents, for example? It is hard to envisage how this could be possible, except via recognition of the phenomenal features of thoughts that happen to be expressed in inner speech or visual imagery. But even if episodes of inner speech were to constitute a kind of thought (which we deny), on no account can the content of the thought be equated with the form of words used. This is because the same sentence can be used to express more than one content, and because many thoughts are only elliptically expressed. So even if we had direct recognitional capacities for the sentences that figure in inner speech, this would not be the same as having a recognitional capacity for the contents of those sentences.

In contrast, a quotational account of our concepts of thought-contents looks quite plausible. For numerous authors have pointed out that we can think about our thoughtcontents via a process of semantic ascent, embedding the content in question within a phrase that effects reference to it (e.g. Evans 1982; Gordon 1996). In particular, one can refer to the content of any given thought $P$ by embedding it within the phrase, "The thought

" Indeed, some have pointed out that thoughts of the form, "I am thinking that P", have the same kind of indubitability and infallibility that have traditionally been associated with thoughts about our own phenomenal experiences (Burge 1996).

Although quotational concepts of propositional content possess some of the properties of phenomenal concepts, it is plain that they don't have the conceptual isolation necessary for the hard problems of consciousness to arise. In particular, one cannot coherently think, "The thought that polar bears are endangered might not have had the content polar bears are endangered." (This would be the analogue of an inverted experience thought-experiment.) This is because the content of a thought is an essential, not an accidental, property of it. Nor can one coherently think, "Someone might have all of the right representational and computational machinery, related in the same sorts of ways to features of the world or to other features of our cognition as occurs in ourselves, but without being capable of the thought that polar bears are endangered." This would be the analogue of a zombie thoughtexperiment. 
We have offered only the barest sketch of an argument against non-perceptual cognitive phenomenology, of course. But it does at least suggest that the case made out against the cognitive phenomenology of perception in Sections 2 and 3 is likely to generalize. The detailed demonstration that this is so must be left for another occasion. $^{12}$

\section{References}

Baars, B. (2002). "The conscious access hypothesis," Trends in Cognitive Science, 6: 47-52.

Balog, K. (1999). "Conceivability, possibility, and the mind-body problem," Philosophical Review, 108: 497-528.

Bayne, T. (2009). "Perceptual experience and the reach of phenomenal content," Philosophical Quarterly.

_- (forthcoming). "The reach of phenomenal consciousness," (submitted).

Block, N. (1995). "A confusion about the function of consciousness," Behavioral and Brain Sciences, 18: 227-47.

- (2002). "The harder problem of consciousness," Journal of Philosophy, 99: 1-35.

Burge, T. (1996). "Our entitlement to self-knowledge," Proceedings of the Aristotelian Society, 96: 91-116.

Burns, B. and Shepp, B. (1988). "Dimensional interactions and the structure of psychological space," Perception and Psychophysics, 43: 494-507.

Carruthers, P. (2000). Phenomenal Consciousness. Cambridge: Cambridge University Press.

_ and Veillet, B. (2007). "The phenomenal concept strategy," Journal of Consciousness Studies, 14: 9-10, 212-36.

Chalmers, D. (1996). The Conscious Mind. Oxford: Oxford University Press.

- (1997). "Availability: The cognitive basis of experience," Behavioral and Brain Sciences, 20: $148-9$.

- (2003). "Phenomenal belief," in Q. Smith and A. Jokic (eds), Consciousness. Oxford: Oxford University Press.

- (2007). "Phenomenal concepts and the explanatory gap," in T. Alter and S. Walter (eds), Phenomenal Concepts and Phenomenal Knowledge. Oxford: Oxford University Press.

Dehaene, S. and Naccache, L. (2001). "Towards a cognitive neuroscience of consciousness: Basic evidence and a workspace framework," Cognition, 79: 1-37.

Dehaene, S., Sergent, C., and Changeux, J. (2003). "A neuronal network model linking subjective reports and objective physiological data during conscious perception," Proceedings of the National Academy of Science, 100: 8520-5.

Dennett, D. (1991). Consciousness Explained. London: Allen Lane.

Dretske, F. (1995). Naturalizing the Mind. Cambridge, MA: MIT Press.

Evans, G. (1982). The Varieties of Reference. Oxford: Oxford University Press.

Farah, M. (2004). Visual Agnosia (2nd edn). Cambridge, MA: MIT Press.

\footnotetext{
${ }^{12}$ We are grateful to Tim Bayne and two anonymous readers for Oxford University Press for their insightful comments on earlier drafts of this essay.
} 


\section{PETER CARRUTHERS AND BÉNÉDICTE VEILLET}

Gordon, R. (1996). "'Radical' simulationism," in P. Carruthers and P. Smith (eds), Theories of Theories of Mind. Cambridge: Cambridge University Press.

Jackson, F. (1982). "Epiphenomenal qualia,” Philosophical Quarterly, 32: 127-36.

- (1986). "What Mary didn't know," Journal of Philosophy, 83: 291-5.

Kosslyn, S. (1994). Image and Brain. Cambridge, MA: MIT Press.

Levine, J. (2001). Purple Haze. Oxford: Oxford University Press.

- (2007). "Phenomenal concepts and the Materialist Constraint," in T. Alter and S. Walter (eds), Phenomenal Concepts and Phenomenal Knowledge. Oxford: Oxford University Press.

Livingston, K., Andrews, J., and Harnad, S. (1998). "Categorical perception effects induced by category learning," Journal of Experimental Psychology: Learning, Memory, and Cognition, 24(3): $732-53$.

Loar, B. (1990). "Phenomenal states," in J. Tomberlin (ed.), Philosophical Perspectives: Action Theory and Philosophy of Mind. Atascadero, CA: Ridgeview Publishing Company, vol. 4, 81-108.

Lycan, W. (1996). Consciousness and Experience. Cambridge, MA: MIT Press.

McDowell, J. (1994). Mind and World. Cambridge, MA: Harvard University Press.

Milner, D. and Goodale, M. (1995). The Visual Brain in Action. Oxford: Oxford University Press. Papineau, D. (2002). Thinking about Consciousness. Oxford: Oxford University Press.

Perry, J. (2001). Knowledge, Possibility, and Consciousness. Cambridge, MA: MIT Press.

Pitt, D. (2004). "The phenomenology of cognition," Philosophy and Phenomenological Research, 59: $1-36$.

Pylyshyn, Z. (2003). Seeing and Visualizing. Cambridge, MA: MIT Press.

Rosenthal, D. (2005). Consciousness and Mind. Oxford: Oxford University Press.

Rubens, A. and Benson, D. (1971). "Associative visual agnosia," Archives of Neurology, 24: 305-16.

Schwitzgebel, E. (2008). "The unreliability of naive introspection," Philosophical Review, 117: $245-73$.

Siewert, C. (1998). The Significance of Consciousness. Princeton, NJ: Princeton University Press. Stoljar, D. (2005). "Physicalism and phenomenal concepts," Mind and Language, 20: 469-94.

Strawson, G. (1994). Mental Reality. Cambridge, MA: MIT Press.

Thompson, B. (2010). “The spatial content of experience," Philosophy and Phenomenological Research: 80 .

Tye, M. (1995). Ten Problems of Consciousness. Cambridge, MA: MIT Press.

- (2000). Consciousness, Color, and Content. Cambridge, MA: MIT Press.

- (2009). Consciousness Revisited. Cambridge, MA: MIT Press. 